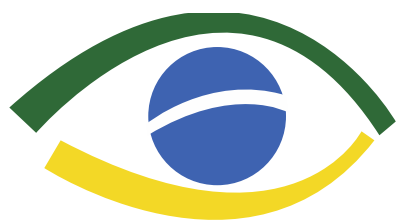

\section{Observatório da Jurisdiçãc Constitucional}

Observatório da Jurisdição Constitucional. Ano 7, no. 2, jul./dez. 2014. ISSN 1982-4564.

\title{
Um olhar sobre a eficácia dos direitos fundamentais nas relações entre particulares
}

\author{
Fernanda Raso Zamorano*
}

Resumo: Os direitos fundamentais, antes reconhecidos tão somente no embate entre Estado e particular, mereceram um novo olhar e passaram a ser entendidos também sob a ótica das relações privadas, com a conseqüente ampliação de seu lastro protetivo aos indivíduos e à sociedade. Diante desse cenário de eficácia irradiante, o presente artigo buscou abordar, inicialmente, a concepção de direitos fundamentais no cenário jurídico nacional e internacional, bem como as teses referentes à aplicabilidade horizontal de tais direitos. Em seguida, dada a relevância do tema, foram explorados acórdãos representativos da jurisprudência do Supremo Tribunal Federal, na tentativa de esclarecer as hipóteses mais comuns de sua utilização.

Palavras-chave: Direitos fundamentais. Eficácia horizontal. Evolução histórica. Teses. Jurisprudência brasileira.

\begin{abstract}
Fundamental rights, as recognized only in the first clash between state and private, deserved a new look and began to be understood also from the perspective of private relations, with the consequent expansion of its protective backing to individuals and society. In this context, this thesis sought to address, initially, the concept of fundamental rights in national and international legal scene as well as the horizontal theses regarding the applicability of such rights. Then, given the importance of the topic, this thesis explore the most representative decisions of the Supreme Court that can clarify the most regular hypotheses of its use.
\end{abstract}

Keywords. Fundamental Rights. Efficacy horizontal. Historical evolution. Theses. Brazilian courts'decisions.

\footnotetext{
* Advogada da União. Especialista em Direito Público pela Universidade Anhanguera. Formada em Direito pela Universidade Federal de Minas Gerais (UFMG).
} 


\section{Introdução}

Secularmente, a concepção de direitos fundamentais inclinou-se a simbolizar e concretizar um limite ao Estado em sua interface com os indivíduos. Sob essa ótica, trata-se de deveres atribuídos ao Estado para com o particular, seja na modalidade de um verdadeiro absteísmo de intervenção (não interferência na esfera de liberdade dos indivíduos), seja no sentido de postulados de proteção.

Não restam dúvidas, pois, sobre a relevância dos direitos fundamentais no Estado Democrático de Direito. Há de se verificar, contudo, de que maneira tais direitos exercem influência sobre as relações estabelecidas na sociedade, sejam entre particulares, seja entre indivíduo-Estado.

A aceitação da aplicabilidade dos direitos fundamentais na relação entre os particulares, nesse contexto, apresenta-se como uma negação à concepção dogmática tradicional que enxerga tais direitos unicamente como oponíveis ao Estado.

Com o advento da Constituição de 1988, novas diretrizes foram impostas à vida social de nosso país. Ademais, estabeleceu-se um novo parâmetro para interpretação e aplicação do Direito positivo pátrio. A Constituição brasileira, como norma máxima no âmbito de um Estado, e fruto de uma forte tendência à "socialização" do Direito que atinge os mais modernos ordenamentos ocidentais, criou novas regras e fixou novos paradigmas não só com relação à organização do Estado, mas também sobre outras áreas do Direito (TARTUCE, 2003).

Nesse sentido, como aponta Carlos Alberto Bittar,

quis o constituinte ampliar o espectro de nossa Constituição, exatamente para direcionar, sob sua ótica, o legislador ordinário, impondo-lhe balizas e limites claros, definidos e expressos, sobre diferentes temas de cunho político, social e econômico, a exemplo de outros sistemas ocidentais em que de há muito se têm imiscuído conotações, principalmente sociais, aos esquemas tradicionais, que reduziam à regulamentação do estado e de suas relações com os cidadãos em seu território a temática constitucional. (BITTAR, 1991, p. 17).

A Constituição Federal passa, então, a interferir no modo de olhar e interpretar não somente os demais ramos do direito, como as relações jurídicas travadas pela sociedade. Imprescindível, pois, a observância da Constituição por todos os atores sociais para que se resguarde a sua observância na realidade da vida histórica concreta do seu tempo, da qual a Constituição não estará desvinculada.

Conquanto não esteja positivada na Constituição da República do Brasil uma norma que imponha a realização direita da vinculação dos entes privados aos direitos fundamentais, é possível inferir por meio de uma interpretação teleológica de seu texto, em especial do art. $5^{\circ}, \S 1^{\circ}$, o fundamento normativo ao 
efeito horizontal dos direitos fundamentais, haja vista que o Estado deve garantir, em todas as esferas, que tais direitos sejam efetivos.

Neste contexto, os partícipes do processo político-constitucional devem ser tutores das expectativas sociais, para transformar a constituição em realidade viva e democrática (CUNHA JÚNIOR, 2004, p. 54).

Como aponta com propriedade Luiz Guilherme Marinoni (2004), as normas consagradoras de direitos fundamentais afirmam valores, os quais incidem sobre a totalidade do ordenamento jurídico e servem para iluminar as tarefas dos órgãos judiciários, legislativos e executivos e as relações travadas pelos particulares. Atribui-se aos direitos fundamentais, assim, uma eficácia irradiante.

Com efeito, o arcabouço constitucional irradia seus efeitos para além das esferas estatais, alcançando também as relações privadas. Sobre o tema, as lições de Ingo Wolfgang Sarlet (2007, p.395) são esclarecedoras:

Para além de vincularem todos os poderes públicos, os direitos fundamentais exercem sua eficácia vinculante também na esfera jurídico privada, isto é, no âmbito das relações jurídicas entre particulares.

Dessa maneira, ao se falar em eficácia horizontal dos direitos fundamentais, busca-se sublinhar o fato de que tais direitos não regulam apenas as relações verticais de poder que se estabelecem entre Estado e cidadão, incidindo também nas relações entre particulares.

A mudança de paradigma decorreu da constatação de que, muitas vezes, era necessário intervir nas relações entre particulares para garantir a igualdade entre eles e a dignidade humana também em tais relações. Por conseguinte, passou-se a entender que a autonomia privada não pode ser considerada um valor em si mesmo, como unidade normativa isolada, sendo merecedora de tutela somente se realizar, de forma positiva, os demais princípios e valores constitucionais. (TEPEDINO, 2004, p. 11).

Assim, como leciona Marinoni (2004), existe eficácia vertical na vinculação do legislador e do juiz. Há também eficácia horizontal - também chamada de "eficácia privada" ou de "eficácia em relação a terceiros" - nas relações entre particulares, embora se sustente que, no caso de manifesta desigualdade entre dois particulares (hipótese de poder econômico social), também existe relação de natureza vertical.

O presente artigo parte, pois, da constatação de que os direitos fundamentais exercem eficácia vinculante também na esfera jurídica privada. $\mathrm{O}$ problema que se coloca diante da eficácia horizontal é o de que nas relações entre particulares há dois (ou mais) titulares de direitos fundamentais, e por isso nelas é impossível afirmar uma vinculação (eficácia) semelhante àquela que incide sobre o Poder Público. (SARLET, 2000, p. 155). 
Partindo da premissa de que a densificação do instituto depende essencialmente das circunstâncias do caso concreto, foram levantadas e exploradas decisões jurisprudenciais do Supremo Tribunal Federal que tratam sobre o assunto, buscando-se compreender as hipóteses de sua utilização e os contornos práticos do tema.

\section{Noção de direitos fundamentais}

O termo "Direitos Fundamentais" surgiu no século XVIII, na França, no curso do movimento político-cultural que levou à Declaração dos Direitos do Homem e do Cidadão, em 1789. Em seguida, dissipou-se pelo pensamento jurídico alemão, "que cunhou a expressão Grundrechte, como um sistema de relações entre indivíduo e o Estado, como fundamento de toda a ordem jurídica liberal" (FERNANDES, 2011, p. 226).

Entende-se por Direitos Fundamentais, aqueles direitos inerentes à própria condição humana e, que estão previstos pelo ordenamento jurídico. Como alerta, com propriedade, Vírgilio Afonso da Silva (2005, p.128), estabelecer um conceito para os direitos fundamentais não é tarefa simples.

Conquanto muitos autores proponham várias definições, o pressuposto teórico de quem se compromete nessa empreitada fica sem elucidações. Por conseguinte, o conceito acaba ficando preenchido de uma imprecisão dogmática.

Na tentativa de apresentar uma visão geral sobre o tema, de modo a possibilitar a compreensão da questão central estudada no presente artigo, devese assentar, primeiramente, que os direitos ora estudados encontram-se no nível do direito positivo, ficando, hoje, afastada qualquer fundamentação amparada no direito natural. A procedência dessa afirmação evidencia-se diante da verificação de que são direitos caracterizados pela historicidade, isto é, são direitos que "nascem, modificam-se e desaparecem" (SILVA, 1999, p. 185).

Além disso, cumpre destacar que os direitos fundamentais possuem natureza constitucional, porquanto são aqueles direitos do ser humano que "[...] nascem e se desenvolvem com as Constituições nas quais foram reconhecidos e assegurados [...]" (SARLET, 2007, p.38). Dessarte, é o ordenamento jurídicoconstitucional de cada Estado que determina quais são os direitos que, no seu território e em um certo momento, são considerados direitos fundamentais.

No Brasil, a Constituição da República classifica, em seu Título II, o gênero "direitos e garantias fundamentais" em cinco espécies, a saber: direitos individuais, direitos coletivos, direitos sociais, direitos à nacionalidade e direitos políticos.

Todavia, deve-se frisar, em consonância com o entendimento do Supremo Tribunal Federal (ADI 939-7/DF), que os direitos fundamentais não se restringem ao artigo $5^{\circ}$ da Constituição Federal de 1988, podendo ser encontrados ao longo do texto constitucional (LENZA, 2008, p. 587). 
Diante disso, releva-se importante a distinção existente entre direitos fundamentais em sentido formal e direitos fundamentais em sentido material. A esse respeito, esclarece Sarlet (2007, p. 88):

De modo geral, os direitos fundamentais em sentido formal podem, na esteira de K. Hesse, ser definidos como aquelas posições jurídicas da pessoa - na sua dimensão individual, coletiva ou social - que, por decisão expressa do LegisladorConstituinte foram consagradas no catálogo dos direitos fundamentais (aqui considerados em sentido amplo). Direitos fundamentais em sentido material são aqueles que, apesar de se encontrarem fora do catálogo, por seu conteúdo e por sua importância podem ser equiparados aos direitos formalmente (e materialmente) fundamentais.

De tal assertiva, extrai-se a importante conclusão de que há direitos fundamentais dispersos em todo o texto da lei fundamental e até mesmo fora dele. Vale lembrar que 0 artigo $5^{\circ}, \S 2^{\circ}$, da Carta Magna, possibilita 0 reconhecimento de direitos decorrentes do regime e dos princípios adotados pela Carta de 1988 ou dos tratados internacionais de que seja parte o Estado brasileiro, de modo a consagrar abertura material dos direitos fundamentais no ordenamento constitucional vigente.

É possível dizer, ainda, relembrando a breve caracterização feita por David Araújo e Serrano Nunes Júnior, que os direitos fundamentais têm como traços distintivos sua universalidade, limitabilidade, concorrência e irrenunciabilidade. José Afonso da Silva ainda acrescenta a inalienabilidade e a imprescritibilidade (LENZA, 2008, p. 590 e 591).

Para a delimitação do tema, não se pode deixar de apresentar a classificação, largamente difundida hodiernamente, que toma por base a ordem cronológica do reconhecimento constitucional de tais direitos.

Os direitos fundamentais, inicialmente, foram concebidos como direitos da liberdade, referentes aos direitos civis e políticos, oponíveis ao Estado, na tentativa de resguardar o indivíduo perante o poder estatal.

Nesse contexto, pretendia-se, sobretudo, fixar uma esfera de autonomia pessoal refratária às expansões do Poder. Daí esses direitos traduzirem-se em postulados de abstenção dos governantes, criando obrigações de não fazer, de não intervir sobre aspectos da vida pessoal de cada indivíduo (MENDES; COELHO; BRANCO, 2008, p. 233).

Em seguida, verifica-se o surgimento dos chamados "direitos da segunda geração", no século XX. São os direitos sociais, culturais e econômicos, bem como os direitos coletivos ou de coletividades, introduzidos no constitucionalismo das distintas formas de Estado social, depois que germinaram por obra da ideologia e da reflexão antiliberal deste século. 
Da mesma maneira que os da primeira geração, esses direitos foram, a princípio, objeto de uma formulação especulativa, em esferas filosóficas e políticas de acentuado cunho ideológico. Seu embasamento teórico, fixando as bases do garantismo social, advém de três documentos derivados dos fatos históricos relatados, quais sejam: a Constituição de Weimar de 1919; a Constituição Mexicana de 1917 e a Declaração dos Direitos do Povo Trabalhador e Explorado, na Rússia revolucionária de 1918.

Nesse contexto, o Estado passa a chamar para si a solução dos problemas sociais, dando ensejo aos chamados direitos prestacionais, positivos, no sentido de um facere por parte do poder público.

Na sequência, surge uma nova dimensão dos direitos fundamentais a ser tutelada, relacionada à essência do ser humano, sua razão de existir, ao destino da humanidade, considerando o ser humano como gênero, não apenas como indivíduo.

A chamada terceira geração surge marcada por profundas mudanças na comunidade internacional (sociedade de massa, crescente desenvolvimento tecnológico e científico) e nas relações econômico-sociais.

O surgimento desta dimensão de direitos tem em vista a constatação da necessidade de atenuar as diferenças entre as nações desenvolvidas e subdesenvolvidas, por meio da colaboração de países ricos com os países pobres.

Cumpre salientar, nos termos de Noberto Bobbio (1992, p. 6), que os direitos de terceira geração emergiram ao lado dos direitos sociais e constituem uma categoria ainda excessivamente heterogênea e vaga, o que dificulta a compreensão do que efetivamente se trata. Pode-se afirmar que o ser humano é inserido em uma coletividade e passa a ter direitos de solidariedade (LENZA, 2008, p. 589).

Dentre os direitos integrantes dessa dimensão, temos aqueles relacionados ao desenvolvimento (progresso), ao meio ambiente, à autodeterminação dos povos, entre outros (NOVELINO, 2008, p. 228).

Há ainda, doutrinadores que defendem a existência de uma quarta geração de direitos fundamentais. Conforme leciona Marcelo Novelino (2008, p. 229), tais direitos foram

introduzidos no âmbito jurídico pela globalização política, compreendem o direito à democracia, informação e pluralismo. Os direitos fundamentais de quarta dimensão compendiam o futuro da cidadania e correspondem à derradeira fase da institucionalização do Estado social sendo imprescindíveis para a realização e legitimidade da globalização política. 
Steinmetz (2004, p. 94), entretanto, refere ser discutível essa posição. Entende que, a rigor, tais direitos seriam direitos de primeira geração, pois seriam reconduzíveis aos direitos políticos. Aponta como direitos de quarta geração os direitos fundamentais ante os avanços da ciência e da tecnologia (como os direitos referentes ao patrimônio genético dos indivíduos e os direitos fundamentais diante da universalização e do desenvolvimento da informática, na proteção de áreas não abrangidas pelos direitos fundamentais de primeira dimensão), direito fundamental à identidade cultural e direito fundamental à morte digna.

A visão dos direitos fundamentais em termos de dimensões, embora não se apresente de modo uniforme entre os doutrinadores, indica o caráter cumulativo da evolução desses direitos no tempo e serve como importante indicativo conceitual, demonstrando a tentativa de se ampliar, cada vez mais, o âmbito de proteção dos indivíduos.

\section{As perspectivas dos direitos fundamentais}

Inicialmente, deve-se esclarecer que as dimensões objetiva e subjetiva dos direitos fundamentais não se confundem com sua eficácia horizontal e vertical. Conforme explica Luiz Guilherme Marioni (2004, p.5), a dimensão objetiva se contrapõe à subjetiva e "tem por fim explicar que as normas de direitos fundamentais - além de poderem ser referidas a um direito subjetivo - também constituem decisões valorativas de ordem objetiva".

Segundo o autor,

afirmar a dupla dimensão - objetiva e subjetiva - dos direitos fundamentais não significa dizer que o direito subjetivo decorre do direito objetivo. O que importa esclarecer, aqui, é que as normas que estabelecem direitos fundamentais, se podem ser subjetivadas, não pertencem somente ao sujeito, mas sim a todos aqueles que fazem parte da sociedade $(2004$, p. 5).

Sendo assim, as normas consagradoras de direitos fundamentais implicam valoração de ordem objetiva e subjetiva, porquanto firmam valores, os quais incidem sobre a totalidade do ordenamento jurídico e dos órgãos do Poder Judiciário, Legislativo e Executivo, de maneira que se atribui aos direitos fundamentais uma eficácia irradiante.

Segundo Luís Roberto Barroso (2003, p. 124), a eficácia irradiante desempenha os papéis de princípio hermenêutico e de mecanismo de controle de constitucionalidade, através da interpretação conforme a Constituição.

No primeiro papel, ela impõe ao operador do direito que, diante da ambigüidade de determinada norma jurídica, opte pela exegese que torne essa norma compatível com a Constituição, mesmo que não seja a exegese mais óbvia 
do preceito. No segundo, permite ao Supremo Tribunal Federal que elimine, por contrariedade à Lei Maior, possibilidades interpretativas de determinada norma, sem redução do seu texto, de modo mais consentâneo com a Lei Fundamental.

Sob a perspectiva subjetiva, os direitos fundamentais outorgam a seus titulares possibilidades jurídicas de impor interesses pessoais em face dos órgãos estatais obrigados. Significa dizer que a dimensão subjetiva "importa na faculdade de impor uma atuação negativa ou positiva aos titulares do Poder Público" (FERNANDES, 2011, p. 224). Nesse âmbito, pode-se dizer que, basicamente, ao falar em direitos fundamentais subjetivos, está-se fazendo referência:

[...] à possibilidade que tem o seu titular (considerado como tal a pessoa individual ou ente coletivo a quem é atribuído) de fazer valer judicialmente os poderes, as liberdades ou mesmo o direito à ação ou às ações negativas ou positivas que lhe foram outorgadas pela norma consagradora do direito fundamental em questão (SARLET, 2007, p. 159).

Assim, os direitos fundamentais em sua perspectiva subjetiva visam conferir ao indivíduo garantia de defesa e de atuação diante da ação do poder público.

Por outro lado, há a perspectiva objetiva dos direitos fundamentais que, embora sua existência seja admitida pela doutrina, ainda não há consenso entre os juristas sobre seu preciso significado. De acordo com Canotilho (2002), o fundamento objetivo das normas de direitos fundamentais tem em vista o seu significado para a coletividade e para o interesse público.

Desse modo, quando se fala na perspectiva objetiva dos direitos fundamentais, busca-se demonstrar que os direitos fundamentais devem ser pensados também do ponto de vista da comunidade, e não só como faculdades ou poderes dos indivíduos.

Nesse contexto, a ótica da dimensão objetiva pode ser compreendida como a base do ordenamento jurídico de um Estado Democrático de Direito, sendo um "verdadeiro norte de eficácia irradiante" que o fundamenta (FERNANDES, 2011, p. 224).

Analisando o tema sob outro enfoque, quando se refere às eficácias vertical e horizontal, deseja-se aludir à distinção entre a eficácia dos direitos fundamentais sobre o Poder Público - denominada "eficácia vertical" e a eficácia dos direitos fundamentais nas relações entre os particulares - "eficácia horizontal", também chamada de "eficácia privada" ou de "eficácia em relação a terceiros" (MARIONI, 2004, p.5). 


\section{Aplicação dos direitos fundamentais nas relações entre particulares}

\subsection{Um breve escorço histórico}

Conforme explica Bernardo Fernandes (2011, p. 259-260), na formulação clássica dos direitos fundamentais, de matriz eminentemente liberal, os direitos fundamentais representavam limites ao exercício do poder do Estado. Com a ruptura paradigmática com o Estado Liberal e com o conseqüente advento do Estado Social, uma nova possibilidade de incidência dos direitos fundamentais foi teorizada para além da dicotomia Estado - Particular.

Cumpre frisar que a chamada eficácia horizontal dos direitos fundamentais - a relação que se dá entre Estado e Particular - continua a existir, porém, além dessa perspectiva, surge a necessidade de se repensar a dinâmica posta para aplicação dos direitos fundamentais, de modo a se defender o particular nas suas relações com outros particulares. A partir dessa necessidade, surgem as teses da eficácia horizontal ou de direitos fundamentais nas relações privadas.

Os debates iniciais sobre o tema surgiram na Alemanha, logo após o advento da Lei Fundamental de Bonn, oportunidade em que se delineou que o dever do Estado de proteção aos direitos fundamentais não estava limitado a uma atividade omissiva, mas também se incluía no rol de condutas esperadas de ações em defesa de lesões ou ameaças que os particulares poderiam vir a sofrer em virtude da ação de outros particulares (FERNANDES, 2011, p. 260).

Nesse sentido:

na Alemanha, embora haja certa hesitação quando se trata de identificar a origem precisa do debate, é possível afirmar que este ganhou consistência a partir da década de cinquenta, quando foi cunhado o célebre termo drittwirkung der grundrechte. Há quem sustente, inclusive, que a própria idéia de eficácia dos direitos fundamentais em relações privadas é uma criação da ciência jurídica alemã, verdadeiro produto made in germany, que mais tarde tornou-se artigo de exportação jurídica (GONÇALVES PEREIRA, 2003, p. 134).

Percebe-se, pois, a evolução do pensamento doutrinário, à medida que se identifica que o Estado não é o único sujeito detentor de poder. Como refere Steinmetz (2004, p. 87), no mundo contemporâneo, a capacidade de condicionar, restringir ou eliminar a liberdade das pessoas (indivíduos ou grupos) não pertence apenas ao Estado. Alguns sujeitos possuem tal capacidade mesmo no âmbito das relações horizontais. Exemplos disso são os grandes grupos industriais e comerciais, os sindicatos, as associações de consumidores, as cooperativas, o Movimento dos Trabalhadores Rurais Sem-Terra, entre outros.

O autor (STEINMETZ, 2004, p. 85) observa que: 
[...] No contexto das sociedades contemporâneas, é um equívoco elementar, próprio do liberalismo míope e dogmático, associar o poder exclusivamente ao Estado, como se o Estado tivesse o monopólio do poder ou fosse a única expressão material e espiritual do poder. Há muito o Estado não é o único detentor de poder - talvez nunca tenha sido o único.

Assentada a origem da teoria da eficácia horizontal, cumpre delimitar suas características principais apontadas pela doutrina e jurisprudência.

\subsection{Delineamentos doutrinários}

De acordo com o grau de influência dos direitos fundamentais, podem ser destacados três modelos: o primeiro, que nega quaisquer efeitos sobre as relações privadas, e mais dois que sustentam a produção de efeitos, um, de forma direta, e outro, apenas indiretamente (NOVELINO, 2011, p. 366).

\subsubsection{Teoria da ineficácia horizontal}

Como aponta Marcelo Novelino (2011, p. 366), dentre as concepções analisadas, a que nega a possibilidade de produção dos efeitos nas relações entre particulares é a que goza de menor prestígio. Trata-se da doutrina do state action, desenvolvida pela Suprema Corte dos Estados Unidos.

Na tradição norte-americana, salvo a $13^{a}$ Emenda, que prevê a proibição de escravidão, todos os demais direitos fundamentais se voltam e vinculam única e exclusivamente o Estado (FERNANDES, 2011, p. 262). Argumenta-se que a literalidade do texto constitucional, que consagra as cláusulas de direitos fundamentais, faz referência apenas aos poderes públicos.

Nesse aspecto, é oportuno lembrar que a Constituição Norte-americana data de 1787, época em que as declarações de direitos tinham por finalidade a proteção das liberdades públicas tão-somente em face do Estado (NOVELINO, 2009, p. 336).

Segundo Daniel Sarmento (2006, p. 197-199), além de não admitir, em princípio, a eficácia horizontal dos direitos fundamentais, a jurisprudência norteamericana tem criado obstáculos à possibilidade de tutela legislativa destes direitos no âmbito das relações privadas.

Não obstante, o que se vê na prática jurisprudencial da Suprema Corte é a utilização de artifícios com o intuito de equiparar os atos privados questionados aos atos estatais (NOVELINO, 2009, P. 337).

Como conclui Silva (2005, p. 99), a finalidade desta doutrina é tentar afastar a impossibilidade de aplicação dos direitos fundamentais aos particulares e definir, ainda que de forma casuística e assistemática, em que situações uma 
conduta privada está vinculada a esses direitos. Cuida-se de uma negação meramente aparente, pois consiste na equiparação dos atos privados aos atos estatais.

\subsubsection{Tese da eficácia mediata ou indireta}

A tese da eficácia horizontal indireta ou mediata dos direitos fundamentais tem como ponto de partida o reconhecimento de um direito geral de liberdade, que propicia aos participantes de uma relação privada a possibilidade de afastarem as disposições de direitos fundamentais, sem a qual a liberdade contratual restaria comprometida.

Esta concepção, segundo aponta Daniel Sarmento (2003, p.210) foi desenvolvida originariamente, em 1956, por Günter Dürig e adotada pela Corte Constitucional da Alemanha.

Para o autor alemão, a proteção constitucional da autonomia privada implica a possibilidade de os indivíduos renunciarem a direitos fundamentais no âmbito das relações privadas, o que, de outra parte, seria inconcebível no que concerne às relações travadas com o poder público (DURIG, Gunther. "Grundrechte und Zivilrechtsprechung". p. 159, apud SILVA, Virgílio Afonso. Op. cit. p.75).

Dessa forma, Dürig propõe uma concepção dualista dos direitos fundamentais. De uma face, implicariam em direitos subjetivos dos cidadãos contra o Estado, e de outra, assegurariam a liberdade contratual dos indivíduos entre si e a autonomia privada (SILVA, p.75).

Desse modo, para os adeptos dessa concepção, a força jurídica dos preceitos constitucionais somente se afirmaria, em relação aos particulares, por meio dos princípios e normas de direito privado. Isso ocorreria através de normas de direito privado - ainda que editadas em razão do dever de proteção do Estado.(MARINONI, 2004, p. 6). Destarte, caberia precipuamente, ao legislador privado, a tarefa de mediar a aplicação dos direitos fundamentais nas relações entre particulares, estabelecendo uma disciplina que se revele em consonância com os valores constitucionais. mediata,

Citando as lições de Canotilho (1993, p. 593), para a teoria da eficácia

os direitos, liberdades e garantias teriam uma eficácia indireta nas relações privadas, pois a sua vinculatividade exerce-se-ia prima facie sobre o legislador, que seria obrigado a conformar as referidas relações obedecendo aos princípios materiais positivados nas normas de direito, liberdades e garantias.

Segundo Robert Alexy (1997, p 243), a aplicação dos direitos fundamentais nas relações entre particulares seria sempre mediada pela atuação 
do legislador (e sua produção normativa ordinária) ou mesmo pelo Juiz que deveria interpretar o direito infraconstitucional (privado) à luz das normas de direitos fundamentais.

Por conseguinte, de acordo com esse modelo, os direitos fundamentais não podem ser invocados diretamente a partir da Constituição por não ingressarem no cenário privado como direitos subjetivos. A incidência direta dos direitos fundamentais aniquilaria a autonomia da vontade, causando uma desfiguração do direito privado (Novelino, 2011, p. 233).

Nesse sentido, a força jurídica dos preceitos constitucionais no âmbito das relações entre particulares incide apenas mediatamente, por meio dos princípios e normas próprias do direito privado, vez que os direitos fundamentais servem apenas para princípios de interpretação das cláusulas gerais e dos conceitos indeterminados, suscetíveis de concretização ou preenchimento de lacunas (Savazzoni, 2009, p. 2).

Essa é a posição majoritária na doutrina alemã, sendo assumida, por exemplo, por Konrad Hesse, para quem tal teoria visaria proteger o núcleo da autonomia privada dos indivíduos.

\subsubsection{Tese da eficácia imediata ou direta}

Hans Carl Nipperdey é apontado como o defensor pioneiro da tese que, originada na década de 50, sustenta a vinculação direta dos particulares aos direitos fundamentais. Segundo o autor, os direitos fundamentais teriam eficácia absoluta, derivando diretamente da Constituição, sendo despicienda qualquer intermediação legislativa para a sua aplicação.

Embora não tenha obtido grande aceitação na Alemanha, é atualmente a teoria majoritária na Espanha, na Itália e em Portugal. De acordo com essa tese, a incidência dos direitos fundamentais deve ser estendida às relações entre particulares, independentemente de qualquer intermediação legislativa.

Segundo seus defensores, os direitos fundamentais, tal como previstos no texto constitucional, já trazem condições de plena aplicabilidade nas relações entre particulares, dispensando qualquer tipo de mediação infraconstitucional. Nesse sentido, com base da perspectiva da máxima efetividade, a Constituição com seu rol de direitos fundamentais - deveria ser aplicada diretamente nas relações entre particulares (FERNANDES, 2011, p. 262).

Os efeitos inerentes aos direitos fundamentais dispensam recursos interpretativos para sua aplicação nas relações privadas, apesar de esta não ocorrer da mesma forma e com a mesma intensidade que se dá em relação aos poderes públicos, pois enquanto estes são responsáveis por gerir o bem da coletividade, aqueles desfrutam de proteção constitucional à autonomia da 
vontade, fundamento da dignidade da pessoa humana (Novelino, 2008, p. 234235).

Esclarece Marinoni (2004, p.6):

De acordo com os teóricos da eficácia imediata, os direitos fundamentais são aplicáveis diretamente em relação aos particulares. Além de normas de valor, teriam importância como direitos subjetivos contra entidades privadas portadoras de poderes sociais ou mesmo contra indivíduos que tenham posição de supremacia em relação a outros particulares. Outros, chegando mais longe, admitem a incidência imediata dos direitos fundamentais em relação a pessoas "comuns". O que importa, nessa última perspectiva, é que se dispensa a intermediação do legislador - e assim as regras de direito privado - e se elimina a idéia de que os direitos fundamentais poderiam ser tomados apenas como regras de interpretação.

\subsubsection{Teoria dos Deveres de Proteção}

Há, ainda, uma quarta teoria, denominada de Teoria dos Deveres de Proteção. Surgiu na doutrina alemã como forma de solucionar a questão dos direitos fundamentais no âmbito das relações privadas e é representada por autores como Claus-Wilhelm Canaris e Klaus Stern.

Essa teoria sustenta não estarem os sujeitos de Direito Privado vinculados diretamente aos direitos fundamentais, como estão os Poderes Públicos. Todavia, o Estado, tanto ao editar normas como ao prestar a jurisdição, está obrigado não apenas a abster-se de violar os direitos fundamentais, como também a protegêlos diante das lesões e ameaças provenientes dos particulares. Por conseguinte, essa teoria diferencia-se da aplicabilidade indireta justamente por impor ao Estado o dever de vigilância

Como lecionou o eminente ministro Luiz Fux, por ocasião do julgamento da ADI 4277, de acordo com a teoria dos deveres de proteção, os direitos fundamentais não cuidam apenas do estabelecimento de relações entre os indivíduos e o Estado, de modo a impor a este último abstenções ou o fornecimento de prestações positivas.

A teoria dos deveres de proteção, embora demande a intervenção do legislador ordinário para que haja a efetiva proteção dos direitos fundamentais, também garante a possibilidade de intervenção do Judiciário, quando necessária, por meio do controle de constitucionalidade das normas de direito privado.

Há de se ressaltar que Daniel Sarmento (2005) aponta para a similaridade dessa teoria, quanto aos seus efeitos, com a teoria da eficácia indireta ou mediata dos direitos fundamentais, que também exige, para a proteção desses direitos, a 
mediação do legislador. No mesmo sentido, Marinoni (2004) afirma que essa eficácia sobre os particulares não exclui a eficácia horizontal mediata ou indireta, que se dá justamente através da lei e da decisão judicial.

Delimitadas as teorias, cumpre discorrer acerca do entendimento da doutrina brasileira.

\title{
4.2.5. O entendimento da doutrina brasileira
}

A Constituição brasileira de 1988 atribuiu significado ímpar aos direitos individuais. Já a colocação do catálogo dos direitos fundamentais no início do texto constitucional denota a intenção do constituinte de lhes emprestar significado especial. A amplitude conferida ao texto, reforça a impressão sobre a posição de destaque que o constituinte quis outorgar a esses direitos (MENDES, 2002, p. 1).

Reconhece-se, pois, de forma inequívoca a supremacia dos direitos fundamentais no ordenamento jurídico brasileiro. Nesse contexto, pode-se afirmar que

\begin{abstract}
no direito pátrio não há qualquer justificativa plausível para se negar a eficácia horizontal dos direitos fundamentais. Este modelo não é coadunável com a triste realidade brasileira na qual as desigualdades sociais estão entre as piores do mundo, impondo a necessidade de uma preocupação ainda maior com a proteção dos direitos fundamentais, sobretudo em relação aos hipossuficientes. As doutrinas jurídicas não podem ser simplesmente reproduzidas ou elaboradas isoladamente da realidade social, política, econômica e cultural na qual se inserem (NOVELINO, 2008, P. 234).
\end{abstract}

Desse modo, o reconhecimento da possibilidade de vinculação dos particulares a direitos fundamentais é uma necessidade, e, apesar de não haver posicionamento expresso nesse sentido na Constituição Federal, é possível encontrar fundamentos que evidenciam o acerto desse entendimento.

Com efeito, como aponta Daniel Sarmento:

(...) vivemos num país injusto, com índices intoleráveis de desigualdade social, em que a opressão é capilar e onipresente. Neste quadro, o reconhecimento da vinculação direta dos particulares aos direitos fundamentais pode servir como importante instrumento para moldar, de acordo com parâmetros de justiça substancial, extraídos da Constituição, a miríade de relações assimétricas travadas na sociedade". (2003,p.84).

Seguindo a lição de Steinmetz (2004, p. 101-123), entende-se que a eficácia dos direitos fundamentais nas relações entre particulares possui como 
principais alicerces o princípio da supremacia da Constituição (ou princípio da constitucionalidade), o postulado da unidade material do ordenamento jurídico, os direitos fundamentais como princípios objetivos e o princípio da dignidade da pessoa humana. Em menor grau, referida eficácia, segundo o autor citado, tem como fundamentos adicionais o princípio constitucional da solidariedade e o princípio da aplicação imediata dos direitos fundamentais.

Segundo Paulo Gustavo Gonet Branco (2002, p. 2), há de se acrescentar, ainda, para a aceitação desse discurso, o postulado da máxima efetividade dos direitos fundamentais.

No Brasil, quase a totalidade dos autores se alinha em aderência à teoria da eficácia direta ou imediata dos direitos fundamentais. Isso porque, à medida que a Constituição estabelece, em seu art. $5^{\circ}, \S 1^{\circ}$, que as normas definidoras dos direitos e garantias fundamentais têm aplicação imediata, consagra o princípio da máxima efetividade. Tal princípio dispõe que, na interpretação dos direitos fundamentais, atribua-se o sentido capaz de conferir a maior efetividade possível para que tais direitos realmente cumpram sua função social.

Impõe-se, portanto, a preferência por opções que favoreçam a efetiva atuação dos direitos fundamentais, corroborando a adoção do modelo que sustenta a aplicabilidade direta às relações particulares. Não há necessidade de utilização de artifícios jurídicos para lhes garantir efetividade (Novelino, 2008, p. 235.).

No mesmo sentido, Jane Reis Gonçalves Pereira (2003, p. 185) argumenta que:

a concepção de que direitos fundamentais incidem diretamente nas relações privadas é uma conseqüência natural e lógica da adoção de um modelo hermenêutico comprometido com o caráter normativo da constituição.

Esse também é o entendimento de Ingo Wolfgang Sarlet (2007, p. 152), colacionado a seguir:

(...) também na ordem constitucional pátria inexiste respaldo suficientemente robusto a sustentar uma negativa no que diz com a vinculação direta dos particulares aos direitos fundamentais, ao menos nas hipóteses em que não tenham por destinatário exclusivo o poder público.

De acordo com parcela da doutrina, esse posicionamento, em princípio, parece acarretar dois maiores problemas, quais sejam: (1) a aplicação direta dos direitos fundamentais entre particulares pode potencializar o papel do juiz à custa do legislador democrático; (2) corre-se o risco de transformar o tribunal constitucional em um "supremo tribunal de conflitos jurídicos-civis" e de assumir, deste modo, um papel que a lei fundamental não conferiu a este tribunal. Tal 
risco se torna mais preocupante no contexto do STF, que julga aproximadamente 100 mil processos por ano (GORZONI, 2006).

Diante desse cenário, torna-se imprescindível observar a maneira como o Supremo Tribunal Federal aborda a questão da aplicação direta dos direitos fundamentais nos conflitos entre particulares. Em uma análise perfunctória, assenta-se que a solução de tais conflitos exige um ônus de argumentação maior dos juízes em cada situação concreta, a fim de se evitar a insegurança jurídica, bem como o desequilíbrio ao poder de freios e contrapesos dos poderes, em razão da concessão de poderes excessivos ao juiz, em detrimento do legislador.

\section{A jurisprudência do STF sobre o tema}

Segundo aponta Bernardo Fernandes (2011, p. 263), sem dúvida, o Brasil vem reconhecendo, tanto doutrinária quanto jurisprudencialmente, a possibilidade de aplicação dos direitos fundamentais nas relações privadas. Não há, porém, na jurisprudência do Supremo Tribunal Federal, uma fundamentação teórica sobre os limites e alcances dessa aplicação.

Nesses termos, cumpre trazer à baila, em princípio, três casos decididos pelo Pretório Excelso que a doutrina aponta como paradigmáticos.

O primeiro dos acórdãos prolatados pelo STF que tangencia o tema se refere à expulsão de associado de cooperativa por deliberação da Assembléia Geral, sem que fossem observadas as regras estatutárias relacionadas à ampla defesa. No Recurso Extraordinário $n^{\circ}$ 158.215/RS, relatado pelo Min. Marco Aurélio, a Corte decidiu que ato de exclusão praticado no âmbito de entidade privada não se furta à observância do direito fundamental ao devido processo legal, a fim de assegurar a ampla defesa, conforme ementa abaixo:

DEFESA - DEVIDO PROCESSO LEGAL - INCISO LV DO ROL DAS
GARANTIAS CONSTITUCIONAIS - EXAME - LEGISLAÇÃO
COMUM. A intangibilidade do preceito constitucional
assegurador do devido processo legal direciona ao exame da
legislação comum. Daí a insubsistência da óptica segundo a
qual a violência à Carta Política da República, suficiente a
ensejar o conhecimento de extraordinário, há de ser direta e
frontal. Caso a caso, compete ao Supremo Tribunal Federal
exercer crivo sobre a matéria, distinguindo os recursos
protelatórios daqueles em que versada, com procedência, a
transgressão a texto constitucional, muito embora torne-se
necessário, até mesmo, partir-se do que previsto na legislação
comum. Entendimento diverso implica relegar à inocuidade
dois princípios básicos em um Estado Democrático de Direito -
o da legalidade e do devido processo legal, com a garantia da
ampla defesa, sempre a pressuporem a consideração de normas
estritamente legais. COOPERATIVA - EXCLUSÃO DE ASSOCIADO
- CARÁTER PUNITIVO - DEVIDO PROCESSO LEGAL. Na hipótese


de exclusão de associado decorrente de conduta contrária aos estatutos, impõe-se a observância ao devido processo legal, viabilizado o exercício amplo da defesa. Simples desafio do associado à assembléia geral, no que toca à exclusão, não é de molde a atrair adoção de processo sumário. Observância obrigatória do próprio estatuto da cooperativa. (RE 158215, Relator(a): Min. MARCO AURÉLIO, SEGUNDA TURMA, julgado em 30/04/1996, DJ 07-06-1996 PP-19830 EMENT VOL-01831-02 PP-00307 RTJ VOL-00164-02 PP-00757).

Ao comentar este caso, Paulo Gustavo Gonet Branco (2002, p.02) observa que:

O acórdão não se deteve em considerações acadêmicas sobre a eficácia dos direitos fundamentais nas relações entre particulares, o que o torna ainda mais sugestivo. A decisão tomou como indiscutível que há normas de direitos fundamentais que incidem diretamente sobre relações entre pessoas privadas. Deixou para os comentadores os adornos doutrinários. O precedente afasta a jurisprudência da linha de entendimento que preconiza a necessidade de uma relação entre Estado e indivíduo, para que se possam invocar direitos fundamentais.

Tempos depois, em 29/10/1996, no histórico julgamento do RE $n$. 161.243/DF, o Supremo Tribunal Federal entendeu que o princípio constitucional da igualdade (isonomia) deve ser observado também nas relações entre particulares. A questão relacionava-se a uma reclamação trabalhista movida por empregado brasileiro de uma companhia aérea francesa e tinha por objetivo estender as prerrogativas do Estatuto Pessoal da empresa, o qual era aplicado somente aos empregados franceses. Na oportunidade, o STF declarou que o direito fundamental à igualdade deve ser observado também nas relações entre particulares, não devendo um trabalhador brasileiro ser discriminado por empresa estrangeira. A ementa da decisão assim preleciona:

CONSTITUCIONAL. TRABALHO. PRINCÍPIO DA IGUALDADE.
TRABALHADOR BRASILEIRO EMPREGADO DE EMPRESA
ESTRANGEIRA: ESTATUTOS DO PESSOAL DESTA:
APLICABILIDADE AO TRABALHADOR ESTRANGEIRO E AO
TRABALHADOR BRASILEIRO. C.F., 1967, art. 153, § $1^{\circ}$; C.F., 1988,
art. 50, caput. I. - Ao recorrente, por não ser francês, não
obstante trabalhar para a empresa francesa, no Brasil, não foi
aplicado o Estatuto do Pessoal da Empresa, que concede
vantagens aos empregados, cuja aplicabilidade seria restrita ao
empregado de nacionalidade francesa. Ofensa ao princípio da
igualdade: C.F., 1967, art. 153, § $1^{\circ}$; C.F., 1988, art. $5^{\circ}$, caput). II. -
A discriminação que se baseia em atributo, qualidade, nota
intrínseca ou extrínseca do indivíduo, como o sexo, a raça, a
nacionalidade, o credo religioso, etc., é inconstitucional.
Precedente do STF: Ag 110.846 (AgRg)-PR, Célio Borja, RTJ


119/465. III. - Fatores que autorizariam a desigualização não ocorrentes no caso. IV. - R.E. conhecido e provido. (RE 161243, Relator(a): Min. CARLOS VELLOSO, Segunda Turma, julgado em 29/10/1996, DJ 19-12-1997 PP-00057 EMENT VOL-01896-04 PP-00756).

Em 2006, no RE 201.819/RJ, o Supremo viu-se novamente diante do tema da exclusão de sócio de associação privada (no caso, a UBC - União Brasileira de Compositores) sem o devido processo legal, contraditório e ampla defesa. Nesse caso paradigmático, a Segunda Turma do Supremo Tribunal Federal aderiu expressamente à tese da vinculação direta dos direitos fundamentais aos particulares.

Distintamente do que ocorreu no RE 158. 215-4, nessa ocasião não havia previsão estatutária acerca do direito de defesa, de modo que a relatora, Min. Ellen Gracie (voto vencido) defendeu que a associação deve deferência, nas relações com seus associados, ao estatuto jurídico da sociedade, o qual constitui desdobramento do princípio da autonomia privada, segundo o qual tudo que não está proibido por lei está permitido e, assim, não havendo previsão legal a tratar do assunto de forma direta e, ainda, havendo previsão estatutária para tanto, a expulsão se faria ato lícito.

O ministro Gilmar Mendes desencadeou a divergência afirmando que os direitos fundamentais previstos na Constituição devem ser aplicados não só nas relações entre os particulares, mas também nas relações entre os particulares envolvendo, por exemplo, pessoas jurídicas privadas e pessoas físicas. Dentre as passagens mais significativas de seu voto, salientou que não era sua intenção "discutir no atual momento qual a forma geral de aplicabilidade dos direitos fundamentais que a jurisprudência desta Corte professa para regular as relações entre particulares"; importava-lhe, isto sim, "ressaltar que o Supremo Tribunal Federal já possui histórico identificável de uma jurisdição constitucional voltada para a aplicação desses direitos às relações privadas".

Por maioria, na linha do voto do ilustre ministro, conclui-se que a expulsão do associado configurou uma violação ao princípio da ampla defesa e que, portanto, padecia de injuricidade. À guisa de ilustração, confira-se a ementa:

SOCIEDADE CIVIL SEM FINS LUCRATIVOS. UNIÃO BRASILEIRA DE COMPOSITORES. EXCLUSÃO DE SÓCIO SEM GARANTIA DA AMPLA DEFESA E DO CONTRADITÓRIO. EFICÁCIA DOS DIREITOS FUNDAMENTAIS NAS RELAÇÕES PRIVADAS. RECURSO DESPROVIDO.

I. EFICÁCIA DOS DIREITOS FUNDAMENTAIS NAS RELAÇÕES PRIVADAS. As violações a direitos fundamentais não ocorrem somente no âmbito das relações entre o cidadão e o Estado, mas igualmente nas relações travadas entre pessoas físicas e jurídicas de direito privado. Assim, os direitos fundamentais assegurados pela Constituição vinculam diretamente não 
apenas os poderes públicos, estando direcionados também à proteção dos particulares em face dos poderes privados.

II. OS PRINCÍPIOS CONSTITUCIONAIS COMO LIMITES À AUTONOMIA PRIVADA DAS ASSOCIAÇÕES. A ordem jurídicoconstitucional brasileira não conferiu a qualquer associação civil a possibilidade de agir à revelia dos princípios inscritos nas leis e, em especial, dos postulados que têm por fundamento direto o próprio texto da Constituição da República, notadamente em tema de proteção às liberdades a garantias fundamentais. $O$ espaço de autonomia privada garantido pela Constituição às associações não está imune à incidência dos princípios constitucionais que asseguram 0 respeito aos direitos fundamentais de seus associados. A autonomia privada, que encontra claras limitações de ordem jurídica, não pode ser exercida em detrimento ou com desrespeito aos direitos e garantias de terceiros, especialmente aqueles positivados em sede constitucional, pois a autonomia da vontade não confere aos particulares, no domínio de sua incidência e atuação, o poder de transgredir ou de ignorar as restrições postas e definidas pela própria Constituição, cuja eficácia e força normativa também se impõem, aos particulares, no âmbito de suas relações privadas, em tema de liberdades fundamentais.

III. SOCIEDADE CIVIL SEM FINS LUCRATIVOS. ENTIDADE QUE INTEGRA ESPAÇO PÚBLICÓ, AINDA QUE NÃO-ESTATAL, ATIVIDADE DE CARÁTER PÚBLICO. EXCLUSÃO DE SÓCIO SEM GARANTIA DO DEVIDO PROCESSO LEGAL. APLICAÇÃO DIRETA DOS DIREITOS FINDAMENTAIS À AMPLA DEFESA A AO CONTRADITÓRIO.

As associações privadas que exercem função predominante em determinado âmbito econômico e/ou social, mantendo seus associados em relações de dependência econômica e/ou social, integram o que se pode denominar de espaço público, ainda que não-estatal. A União Brasileira de Compositores - UBC, sociedade civil sem fins lucrativos, integra a estrutura do ECAD e, portanto, assume posição privilegiada para determinar a extensão do gozo e fruição dos direitos autorais de seus associados. A exclusão de sócio do quadro social da UBC, sem qualquer garantia de ampla defesa, do contraditório, ou do devido processo constitucional, onera consideravelmente o recorrido, o qual fica impossibilitado de perceber os direitos autorais relativos à execução de suas obras. A vedação das garantias constitucionais do devido processo legal acaba por restringir a própria liberdade de exercício profissional do sócio. O caráter público da atividade exercida pela sociedade e a dependência do vínculo associativo para o exercício profissional de seus sócios legitimam, no caso concreto, a aplicação direta dos direitos fundamentais concernentes ao devido processo 
legal, ao contraditório e à ampla defesa (art. 50, LIV, e LV, $\mathrm{CF} / 88$ ).

\section{RECURSO EXTRAORDINÁRIO DESPROVIDO.}

(STF - RE 201819 /RJ - Órgão Julgador: 2a Turma, Rel. Min. ELLEN GRACIE - Relator p/ Acórdão: Min. GILMAR MENDES, DJ 27.10.2006).

Esses três julgados supracitados são paradigmáticos na jurisprudência do STF. Em outros casos, contudo, em que não há menção expressa à eficácia horizontal dos direitos fundamentais, pode-se observar que o tema foi tratado pelos ministros.

Nesse contexto, aponta-se como exemplo o HC 82.424/RS, de relatoria do Ministro Maurício Correia, em 2003, em que a vinculação horizontal permeou a decisão, embora não explicitamente. No caso, Siegfried Ellwanger foi condenado pelo crime tipificado no art. 20 da Lei 7.716/89, com a redação dada pela Lei 8.081/90, por ter, na qualidade de escritor e sócio da empresa "Revisão Editora Ltda.", editado, distribuído e vendido ao público obras anti-semitas de sua autoria e de outros autores nacionais e estrangeiros, que sustentavam mensagens discriminatórias, buscando, com isso, incitar ódio contra o povo judaico.

Trata-se, com efeito, de um conflito entre particulares, sendo que nos pólos da relação encontram-se dois sujeitos privados, estando em jogo direitos fundamentais de ambos os lados (liberdade da expressão de Ellwanger versus direito à igualdade, dignidade e não discriminação). Seria o caso de aplicação mediata dos direitos fundamentais, uma vez que o legislador já ponderou os valores em conflito, decidindo que deve prevalecer o combate à discriminação, sendo o racismo um crime imprescritível. Embora alguns ministros tenham tentado modificar a ponderação do legislador, de modo a impor sua própria interpretação, ao final, decidiu-se por maioria pela manutenção da condenação e pelo indeferimento do habeas corpus. Elucidativa a transcrição do seguinte trecho da ementa:

(...) 13. Liberdade de expressão. Garantia constitucional que não se tem como absoluta. Limites morais e jurídicos. O direito à livre expressão não pode abrigar, em sua abrangência, manifestações de conteúdo imoral que implicam ilicitude penal. 14. As liberdades públicas não são incondicionais, por isso devem ser exercidas de maneira harmônica, observados os limites definidos na própria Constituição Federal (CF, artigo $5^{\circ}$, $\S 2^{\circ}$, primeira parte). $\mathrm{O}$ preceito fundamental de liberdade de expressão não consagra o "direito à incitação ao racismo", dado que um direito individual não pode constituir-se em salvaguarda de condutas ilícitas, como sucede com os delitos contra a honra. Prevalência dos princípios da dignidade da pessoa humana e da igualdade jurídica. 15. "Existe um nexo 
estreito entre a imprescritibilidade, este tempo jurídico que se escoa sem encontrar termo, e a memória, apelo do passado à disposição dos vivos, triunfo da lembrança sobre o esquecimento". No estado de direito democrático devem ser intransigentemente respeitados os princípios que garantem a prevalência dos direitos humanos. Jamais podem se apagar da memória dos povos que se pretendam justos os atos repulsivos do passado que permitiram e incentivaram o ódio entre iguais por motivos raciais de torpeza inominável. 16. A ausência de prescrição nos crimes de racismo justifica-se como alerta grave para as gerações de hoje e de amanhã, para que se impeça a reinstauração de velhos e ultrapassados conceitos que a consciência jurídica e histórica não mais admitem. Ordem denegada.

(HC 82424, Relator(a): Min. MOREIRA ALVES, Relator(a) p/ Acórdão: Min. MAURÍCIO CORRÊA, Tribunal Pleno, julgado em 17/09/2003, DJ 19-03-2004 PP-00017 EMENT VOL-02144-03 PP-00524).

Outro caso emblemático julgado pelo STF refere-se à questão da penhorabilidade do bem de família do fiador em contrato de locação, marcando uma mudança de posicionamento da Corte. No RE 407.688, debateu-se o seguinte problema: a penhorabilidade do bem de família do fiador de contrato de locação persiste com o advento da Emenda Constitucional 26/2000, que ampliou $\mathrm{o}$ art. $6^{\circ}$ da CF, incluindo a moradia entre os direitos sociais?

Conforme exposto no voto do Min. Joaquim Barbosa, nesse caso, a situação é caracterizada expressamente como colisão de direitos fundamentais entre particulares, sendo que está, de um lado, o direito à moradia (art. $6^{\circ}, \mathrm{CF}$ ), que é um direito social constitucionalmente assegurado e, em princípio, exige uma prestação do Estado; de outro, o direito à liberdade, em sua mais pura expressão, ou seja, a da autonomia da vontade, exteriorizada, no caso concreto, na faculdade que tem cada um de obrigar-se contratualmente e, por consequência, de suportar os ônus dessa livre manifestação de vontade.

O eminente ministro continua afirmando que é possível, em certas circunstâncias, um direito fundamental ser aplicado da mesma forma que na relação entre Estado-indivíduo no âmbito privado. Para sustentar sua posição, cita, inclusive, o Recurso Extraordinário 201.819, já analisado no presente trabalho como um caso paradigmático da jurisprudência do Pretório Excelso.

O Min. Sepúlveda Pertence também identificou o caso como relacionado a eficácia horizontal dos direitos fundamentais. Segundo seu entendimento, o problema a ser enfrentado pelo STF é o de "dar efetividade ao direito à moradia, não só com relação às prestações positivas relativas ao Estado, mas também à chamada eficácia horizontal desse direito, nas relações privadas". No entanto, segundo este julgador, na linha do relator, Min. Cezar Peluso e dos fundamentos vencedores, os valores em conflito são as duas faces do direito à moradia - 
direito do fiador à sua propriedade e do locatário a habitação, por meio de contrato de aluguel. À guisa de ilustração, transcreve-se a ementa do mencionado julgado:

FIADOR. Locação. Ação de despejo. Sentença de procedência. Execução. Responsabilidade solidária pelos débitos do afiançado. Penhora de seu imóvel residencial. Bem de família. Admissibilidade. Inexistência de afronta ao direito de moradia, previsto no art. $6^{\circ}$ da CF. Constitucionalidade do art. $3^{\circ}$, inc. VII, da Lei $n^{\circ} 8.009 / 90$, com a redação da Lei $n^{\circ} 8.245 / 91$. Recurso extraordinário desprovido. Votos vencidos. A penhorabilidade do bem de família do fiador do contrato de locação, objeto do art. $3^{\circ}$, inc. VII, da Lei $n^{\circ} 8.009$, de 23 de março de 1990, com a redação da Lei n 8.245 , de 15 de outubro de 1991, não ofende o art. $6^{\circ}$ da Constituição da República.

(RE 407688, Relator(a): Min. CEZAR PELUSO, Tribunal Pleno, julgado em 08/02/2006, DJ 06-10-2006 PP-00033 EMENT VOL02250-05 PP-00880 RTJ VOL-00200-01 PP-00166 RJSP v. 55, n. 360,2007 , p. 129-147).

Em 2010, foi proferida decisão monocrática em medida cautelar em ação cautelar, também relacionada à vinculação horizontal dos direitos fundamentais, em especial ao direito de resposta - que, esclareça-se, compõe o catálogo das liberdades fundamentais relacionadas à liberdade de expressão. Segundo o eminente relator, Min. Celso de Mello,

\footnotetext{
"se é certo que o ordenamento constitucional brasileiro ampara a liberdade de expressão, protegendo-a contra indevidas interferências do Estado ou contra injustas agressões emanadas de particulares, não é menos exato que essa modalidade de direito fundamental - que vincula não só o Poder Público como, também, os próprios particulares - encontra, no direito de resposta (e na relevante função instrumental que ele desempenha), um poderoso fator de neutralização de excessos lesivos decorrentes da liberdade de comunicação, além de representar um significativo poder jurídico deferido a qualquer interessado para se defender de qualquer notícia ou opinião inverídica, ofensiva ou prejudicial (AC 2695 MC, Relator(a): Min. CELSO DE MELLO, julgado em 25/11/2010, publicado em PROCESSO ELETRÔNICO DJe-231 DIVULG 30/11/2010 PUBLIC 01/12/2010, grifado).
}

$\mathrm{Na}$ linha de argumentação exposta na decisão referida, o ministro destaca que a oponibilidade do direito de resposta a particulares sugere reflexão em torno da inteira submissão das relações privadas aos direitos fundamentais, o que permite estender, com força vinculante, ao plano das relações de direito privado, a cláusula de proteção das liberdades e garantias constitucionais. 
Tal assertiva, a toda evidência, como bem aponta o ilustre magistrado, coloca em destaque o tema da eficácia horizontal dos direitos básicos e essenciais assegurados pela Constituição da República, tal como tem acentuado o magistério da doutrina, em lições que possuem o beneplácito da jurisprudência constitucional do Supremo Tribunal Federal.

Recentemente, na ADI 4277, acerca da união homoafetiva, da rica fundamentação exposta nos votos dos eminentes ministros, é possível extrair lições acerca da aplicabilidade horizontal dos direitos fundamentais.

Em especial, o ministro Luiz Fux ressaltou que há que se vislumbrar a existência da pertinência temática em virtude da cognominada teoria dos deveres de proteção (Schutzpflichten), relevante consectário da dimensão objetiva dos direitos fundamentais. Conforme lições do jurista,

\begin{abstract}
a doutrina da perspectiva objetiva dos direitos fundamentais tem berço no direito alemão, forte na consagração dos direitos fundamentais não só como direitos subjetivos do indivíduo em face do Estado, mas também como decisões valorativas de cunho objetivo da Constituição, espraiando sua eficácia sobre todo o direito positivo, de modo a orientar o exercício das funções legislativa, administrativa e judiciária. Traduz-se na "mais-valia" jurídica a que se refere JOSÉ CARLOS VIEIRA DE ANDRADE (Os Direitos Fundamentais na Constituição Portuguesa de 1976. 2. edição. Coimbra: Almedina, 2001, p. 138), vale dizer, um reforço de juridicidade das normas de direitos fundamentais, que disporiam de outros efeitos para além daqueles relacionados com a perspectiva subjetiva.Serve a teoria dos deveres de proteção como meio de vinculação dos particulares aos direitos fundamentais assegurados pela Constituição. Com isso, o Estado não fica apenas obrigado a abster-se da violação dos direitos fundamentais, como também a atuar positivamente na proteção de seus titulares diante de lesões e ameaças provindas de terceiros, seja no exercício de sua atividade legislativa, administrativa ou jurisdicional. (ADI 4277, Relator(a): Min. AYRES BRITTO, Tribunal Pleno, julgado em 05/05/2011, DJe-198 DIVULG 13-10-2011 PUBLIC 14-102011 EMENT VOL-02607-03 PP-00341).
\end{abstract}

De todo o colacionado, observa-se, pois, que o Supremo Tribunal Federal se alinha em favor da aplicabilidade dos direitos fundamentais nas relações entre particulares. Todavia, esta atuação prática não se assemelha a uma plena consciência do "novo horizonte hermenêutico", uma vez que se constata ausência de fundamentação teórica, por parte do tribunal superior.

Cumpre frisar que o voto do Ministro Luiz Fux pode significar um novo posicionamento, mais atento, do STF à questão. Até o momento, contudo, ainda falta esclarecer os parâmetros através dos quais essa vinculação se manifesta, estabelecendo de maneira mais precisa os contornos de tal eficácia. 


\section{Conclusão}

A evolução do pensamento doutrinário e jurisprudencial, somada ao advento da Constituição de 1988, que consagrou uma série de direitos fundamentais, alterou substancialmente a concepção da eficácia dos direitos fundamentais, atribuindo a eles eficácia irradiante, abrangendo também as relações entre particulares.

A percepção de que os direitos fundamentais não poderiam ficar confinados tão somente ao âmbito das relações dos poderes públicos, recebeu elaboração doutrinária, em especial, com a descoberta objetiva de tais direitos.

Conquanto não positivado expressamente na Constituição da República, o entendimento da vinculação horizontal dos direitos humanos alterou a compreensão dada pelo ordenamento jurídico ao mundo privado, de maneira que, sob uma leitura constitucional, passou-se a entender que as relações privadas também devem merecem um maior grau de tutela.

Conforme conclui Pedro Lenza (2008, p. 595), sem dúvida, cresce a teoria da aplicação direta dos direitos fundamentais às relações privadas, notadamente diante de atividades privadas que tenham um certo "caráter público", a exemplo de escolas, clubes associativos, relações de trabalho.

As relações que os particulares estabelecem entre si são as mais variadas, o que gera uma multiplicidade de situações de sujeição, sendo que haverá, em cada uma delas, circunstâncias específicas a se ponderar sobre a aplicação dos direitos fundamentais, tendo como norte, em especial, o postulado máximo, estruturante da sociedade, da dignidade da pessoa humana.

Com efeito, para que tal postulado seja efetivamente respeitado, deve-se coibir abusos tanto sob a ótica do Estado, como sob a perspectiva dos sujeitos de direito privado, sendo que não se pode evitar a prática de arbitrariedades por parte de um particular em prejuízo de outro sem que se aceite a eficácia de direitos fundamentais nas relações entre particulares.

Dessarte, o reconhecimento da eficácia horizontal dos direitos fundamentais reflete uma preocupação com a construção de uma ordem constitucional mais sensível e atenta aos problemas e desafios da sociedade contemporânea, que se manifestam não somente nas relações entre Estado e indivíduo, mas também na imensa gama de relações privadas que são travadas cotidianamente.

Por meio de pesquisa jurisprudencial, constatou-se que, embora o tema tenha grande repercussão doutrinária, seus limites ainda não foram bem delimitados pelo Pretório Excelso, considerando-se as esparsas produções jurisprudenciais do STF limitam-se a reconhecer a aplicabilidade vertical, não aprofundando, contudo, sobre os contornos do tema. 
Um dos direitos fundamentais que o Supremo Tribunal Federal já apontou como de incidência no âmbito dos relacionamentos privados é o direito de ampla defesa, que foi considerado como de observância obrigatória, em se tratando de exclusão de sócio ou de membro de associação particular. Também já foi reconhecida a eficácia horizontal dos direitos fundamentais no que toca aos direitos de isonomia e de liberdade de expressão.

Há de se ressaltar que é imprescindível reservar ao tema maior estudo. Isso porque, se, por um lado, ele reforça o compromisso humanitário que permeia a Constituição da República de 1988, tornando realmente palpáveis os fundamentos de dignidade humana, justiça social, liberdade e igualdade, de outra parte, ele carrega o fardo da possibilidade do arbítrio judicial.

O debate deve se desenrolar em torno da investigação dos direitos fundamentais que podem ter incidência sobre as relações entre particulares e em que medida isso pode ocorrer. Há de presidir tal exame o cotejo, em cada caso, dos reclamos dos direitos fundamentais com as exigências do princípio da autonomia privada - princípio que se liga à autodeterminação do indivíduo, fonte da sua responsabilidade social e jurídica e elemento informador da noção da dignidade humana (BRANCO, 2002, p. 3).

É que, a toda evidência, a perda de clareza conceitual do que seja essa vinculação horizontal pode acarretar uma ameaça à autonomia privada, representando incompatibilidade com os princípios democráticos e, sobretudo, insegurança jurídica.

Portanto, para evitar o subjetivismo judicial, o casuísmo desmedido e, por consequência, a insegurança jurídica, deve haver a preocupação em estabelecer parâmetros específicos de aplicação desses direitos aos particulares para que a liberdade individual não seja subjugada.

\section{Referências Bibliográficas}

ANDRADE, José Carlos Vieira de. Os direitos, liberdades e garantias no âmbito das relações entre particulares. In: Constituição, Direitos Fundamentais e Direito Privado (org. por Ingo Wolfgang Sarlet), Porto Alegre, Livraria do Advogado, 2003.

ALEXY, Robert. Teoría de los derechos fundamentales. (Trad.) Ernesto Garzón Valdés. Madrid: Centro de Estudios Constitucionales, 1997.

BARROSO, Luiz Roberto. Neoconstitucionalismo e Constitucionalização do Direito Civil (O Triunfo Tardio do Direito Constitucional no Brasil), Revista Eletrônica sobre a Reforma do 
Estado, Salvador, Instituto Brasileiro de Direito Público, no. 9, março/abril/maio, 2007. Disponível em: <www.direitodoestado.com.br/rere.asp>. Acesso em 11.02.2011.

- O Direito Constitucional e a efetividade de suas normas - limites e possibilidades da Constituição Brasileira. 7 ed. ampl. e atual. Rio de Janeiro: Renovar, 2003.

BITTAR, Carlos Alberto. Constituição de 1988 e o Direito Civil. São Paulo: Revista dos Tribunais, 1991.

BOBBIO, Norberto. A era dos direitos. Tradução de Carlos Nelson Coutinho. Rio de Janeiro: Campus, 1992.

BRANCO, Paulo Gustavo Gonet. Associação, expulsão de sócios e direitos fundamentais. Revista Diálogo Jurídico, Salvador, CAJ - Centro de Atualização Jurídica, n. 13, abr.-maio, 2002. Disponível em: < http://www.direitopublico.com.br/PDF_13/DIALOGO-JURIDICO13-ABRIL-MAIO-2002-PAULO-GUSTAVO-GONET.pdf>. Acesso em 20.07.2012.

CANARIS, Claus-Wilhelm. Direitos Fundamentais e Direito Privado. Coimbra: Almedina, 2003

A influência dos direitos fundamentais sobre o direito privado na Alemanha. In: Constituição, Direitos Fundamentais e Direito Privado (org. por Ingo Wolfgang Sarlet), Porto Alegre: Livraria do Advogado, 2003.

CANOTILHO, José Joaquim Gomes. Direito Constitucional. Coimbra: Almedina, 1993.

Direito Constitucional e Teoria da Constituição. Coimbra: Almedina, 2002.

CUNHA JÚNIOR, Dirley da. Controle judicial das omissões do poder público: em busca de uma dogmática constitucional transformadora à luz do direito fundamental à efetivação da constituição. São Paulo: Saraiva, 2004.

FERNANDES. Bernando Gonçalves. Curso de Direito Constitucional. $3^{\text {a }}$. ed. Editora Lumen Juris. 2011.

GORZONI, Paula Fernanda Alves da Cunha. Supremo Tribunal Federal e a Vinculação dos Direitos Fundamentais nas Relações entre Particulares. Monografia apresentada à Sociedade Brasileira de Direito Público, SBDP/SP, 2007.

LENZA, Pedro. Direito Constitucional Esquematizado. 12a. Ed. rev. atual. e ampl. São Paulo: Saraiva, 2008. 
MARINONI, Luiz Guilherme. O direito à tutela jurisdicional efetiva na perspectiva da teoria dos direitos fundamentais. Jus Navigandi, Teresina, ano 9, n. 378, 20 jul. 2004. Disponível em: <http://jus.com.br/revista/texto/5281>. Acesso em: 10 mar. 2012.

MENDES, G. F.; COELHO, I. M.; BRANCO, P. G. G. Curso de Direito Constitucional. $2^{\mathrm{a}}$. ed. São Paulo: Saraiva, 2008.

MENDES, Gilmar. Os direitos fundamentais e seus múltiplos significados na ordem constitucional. Revista Diálogo Jurídico, Salvador, CAJ - Centro de Atualização Jurídica, $\mathrm{n}^{\circ}$. 10, janeiro, 2002. Disponível na Internet: <http://www.direitopublico.com.br>. Acesso em: 02 de maio de 2012.

NOVELINO, Marcelo. Direito Constitucional. $2^{\mathrm{a}}$ ed. São Paulo: Método, 2008.

PERLINGIERI, Pietro. Perfis do Direito Civil: Introdução ao Direito Civil Constitucional. (Trad.) M. C. de Cicco. Rio de Janeiro: Renovar, 1999.

PEREIRA, Jane Reis Gonçalves. Apontamentos sobre a aplicação das normas de direito fundamental nas relações jurídicas entre particulares apud $A$ nova interpretação constitucional - ponderação, direitos fundamentais e relações Privadas. 2 ed. rev. e atual. Rio de Janeiro: Renovar, 2003.

2006.

Interpretação constitucional e direitos fundamentais. Rio de Janeiro: Renovar,

SARLET. Ingo Wolfgang. Direitos fundamentais e direito privado: algumas considerações em torno da vinculação dos particulares aos direitos fundamentais, in: $A$ constituição concretizada - Construindo pontes com o público e o privado, Porto Alegre: Livraria do Advogado, 2000.

A Eficácia dos Direitos Fundamentais. Porto Alegre: Livraria do Advogado, 2007.

Dignidade da pessoa humana e direitos fundamentais na Constituição Federal de 1988. $5^{a}$. ed. Porto Alegre: Livraria do Advogado. 2007. p. 152.

SARMENTO, Daniel. Direitos fundamentais e relações privadas. 2.ed. Rio de Janeiro: Lumen Juris, 2006.

Os princípios constitucionais da liberdade e da autonomia privada. Boletim Científico 14, 2005. 
. A vinculação dos particulares aos direitos fundamentais no direito comparado e no Brasil, In: BARROSO, Luís Roberto (Org.). A nova interpretação constitucional: ponderação, direitos fundamentais e relações privadas. Rio de Janeiro: Renovar, 2003.

SILVA. Virgílio Afonso da. A constitucionalização do direito: os direitos fundamentais nas relações entre particulares. São Paulo: Malheiros, 2005.

STEINMETZ, Wilson Antônio. A Vinculação dos Particulares a Direitos Fundamentais. São Paulo: Malheiros, 2004.

TARTUCE, Flávio. Direito Civil e Constituição. Artigo publicado na obra: "Constituição Federal - 15 anos". (Coords.): TAVARES, André Ramos; FERREIRA, Olavo A.V. Alves; LENZA, Pedro. Editora: Método, 2003.

TEPEDINO, Gustavo. Premissas metodológicas para a constitucionalização do direito civil. In: Temas de Direito Civil. 3. ed. Rio de Janeiro: Renovar, 2004.

\section{Legislação e Jurisprudência}

BRASIL. Constituição da República Federativa do Brasil. Brasília, DF: Senado, 1988.

BRASIL. SUPREMO TRIBUNAL FEDERAL. ADI 4277, Relator(a): Min. AYRES BRITTO, Tribunal Pleno, julgado em 05/05/2011.

AC 2695 MC, Relator(a): Min. CELSO DE MELLO, julgado em 25/11/2010, publicado em PROCESSO ELETRÔNICO DJe-231 DIVULG 30/11/2010 PUBLIC 01/12/2010.

HC 82424, Relator(a): Min. MOREIRA ALVES, Relator(a) p/ Acórdão: Min. MAURÍCIO CORRÊA, Tribunal Pleno, julgado em 17/09/2003, DJ 19-03-2004.

Recurso Extraordinário 201819 /RJ - Órgão Julgador: $2^{\text {a }}$ Turma, Rel. Min. ELLEN GRACIE - Relator p/ Acórdão: Min. GILMAR MENDES, DJ 27.10.2006.

Recurso Extraordinário 158215, Relator(a): Min. MARCO AURÉLIO, Segunda Turma, julgado em 30/04/1996, DJ 07-06-1996. 
Recurso Extraordinário 161243, Relator(a): Min. CARLOS VELLOSO, Segunda Turma, julgado em 29/10/1996, DJ 19-12-1997.

Recurso Extraordinário 407688, Relator(a): Min. CEZAR PELUSO, Tribunal Pleno, julgado em 08/02/2006, DJ 06-10-2006.

Artigo recebido em 04 de outubro de 2014. Artigo aprovado para publicação em 17 de novembro de 2014.

DOI: $10.11117 / 1982-4564.07 .16$ 